Acta Poetica $35 \cdot 2$

JULIO-DICIEMBRE

$2014(83-96)$

\title{
La poesía de Efrén Hernández: visión autoscópica de la vida y la experiencia espiritual
}

\author{
Tatiana Bubnova
}

Se nos presenta una serie de temas, motivos e inquietudes éticas y religiosas, recurrentes en la poco estudiada obra poética de Efrén Hernández. Destacan las temáticas de la vida interior y de la experiencia espiritual manifiestas en la búsqueda de Dios y de la trascendencia, en el viaje espiritual y mirada autoscópica del hombre, así como en el amor humano, y en la interrogante sobre el bien y el mal. Estas cuestiones tradicionales en la lírica religiosa, son tratadas aquí de manera no ortodoxa. Efrén Hernández recurre a la inversión y a la ironía para subvertir los motivos religiosos: la búsqueda es anhelo de rapto místico mas no consumado, deseo infructuoso de unión con la trascendencia. Asimismo, las contradicciones humanas que derivan de las oposiciones de la carne y del espíritu, así como de la razón y la pasión, que nos llevan a una poética del rechazo y de la renuncia.

PALABRAS ClAVE: Visión autoscópica, Efrén Hernández, poesía, experiencia espiritual, mística.

A series of ethical and religious themes, motives and concerns are shown, which are recurrent in the less studied poetic work of Efrén Hernández. Standing out are the themes of interior life and spiritual experience, manifested in the search for God and transcendence, in the spiritual journey and autoscopic regard of man, as well as in human love and in the question regarding good and evil. These traditional issues of lyric poetry are treated here in an unorthodox manner. Efrén Hernández uses inversion and irony to subvert the religious motives: the search is a longing for mystical rapture, yet not accomplished, an unfructuous desire of union with transcendence. Likewise, human contradictions derived from the oppositions of flesh and spirit, as well as reason and passion, which lead to a poetic of rejection and renouncement. 
KEYWORDS: Autoscopic vision, Efrén Hernández, poetry, spiritual experience, Mysticism.

Fecha de recepción: 20 de agosto de 2013

Fecha de aceptación: 20 de noviembre de 2013 
Tatiana Bubnova

Universidad Nacional Autónoma de México

Instituto de Investigaciones Filológicas

\section{La poesía de Efrén Hernández: visión autoscópica de la vida y la experiencia espiritual}

La poesía lírica, en realidad, no dispone de un número exagerado de temas que la alimenten. Vida y muerte, el sentido de la vida, amor, eternidad y brevedad del tiempo individual, naturaleza y urbe, trabajo, creación, destino y postura del poeta ante el mundo, cultura y el pasado histórico, comunicación con la divinidad y la desesperación del descrédito, están entre las preocupaciones permanentes de los poetas; sin duda pocas más podrían agregarse a esta provisional lista. Desde luego, la infinita variedad de las manifestaciones de lo eterno y de lo metafísico en un tiempo concreto es lo que constituye un inconfundible rostro poético. La mirada dirigida al interior de un alma en su relación con Dios y, desde allí, hacia el mundo cuya estructura hace poner en duda la bondad del proyecto divino, es la autoscopía de la trayectoria espiritual que me ocupa aquí. La poesía religiosa asociada con el orden eclesiástico en ciertos ámbitos nacionales se apropió de la misma idea de lo espiritual, concepto que sin duda tiene la capacidad de abarcar una cosmovisión compleja sin que implique necesariamente mediaciones institucionales. Pero la poesía en lengua española ha elaborado un marco discursivo apoyado en la institucionalidad de lo divino dejándonos en herencia modelos más excelsos de discurso poético para expresar la espiritualidad. Es a partir de esta concepción de la vida interior del sujeto que hay que leer la producción poética de Efrén Hernández, marco discursivo 
del que el poeta está muy consciente y cuyo sentido en ocasiones invierte y, si se me permite la apreciación, pervierte, resbalándose ante la imperfección de la vida, poniendo en duda sus propias fuerzas.

"Le importa más el espíritu generador del arte que el producto en sí" (Bosquejos, 13), dice la investigadora de la obra de Efrén Hernández, Lourdes Franco. El misterio de la creatividad del ser humano interesa más allá de su obra, prevalece la inquietud acerca del autor como fuente de una determinada actitud artística. Postura crítica ciertamente peculiar, generalmente asociada con la poesía. El autor del que hablo aquí expresó alguna vez una opinión semejante, que comparto respecto de su propia obra. Efrén Hernández (1904-1958), autor del famoso cuento Tachas, y apodado, en consecuencia, Tachitas; sujeto que, siendo coeditor de la revista América, fue el que alentó a publicar sus escritos nada menos que a Juan Rulfo; ${ }^{1}$ es una personalidad evanescente y enigmática. Dejó una obra que no ha generado suficiente respuesta crítica, ante todo porque no cabe en los moldes mediante los cuales nos solemos explicar la escritura de una época. Entre los "contemporáneos" y los de la "novela de la revolución", ${ }^{2}$ entre las vanguardias y el realismo social, es una figura atípica, a la que en algún momento se le calificó como vanguardista, no sé si con suficiente justeza (Rodríguez, "La vanguardia", 101-113). A mi modo de ver, su originalidad consiste, aparte de sus propuestas formales en la narrativa, en el hecho de instaurar una ética personalista en un contexto donde solía prevalecer una explicación "sociológica" de los fenómenos abordados por el arte así como de la existencia del arte mismo. Desde una óptica contraria, había que privilegiar el arte de la palabra como tal, sin considerar sus referencias extraliterarias. La obra y la personalidad de Efrén Hernández (EH, a partir de ahora) no se explican fácilmente por ninguno de los dos enfoques: ni desde la sociología, ni desde el formalismo.

${ }^{1}$ El propio eH lo consigna, con detalles, en una nota de América, en 1948 (ver Bosquejos, 41).

2 Me adhiero a la opinión de Rafael Olea, quien en un reciente artículo propone abandonar el concepto histórico-literario de "novela de la revolución mexicana", que deja de lado manifestaciones literarias importantes fuera del marco de la novela, para sustituirlo por el de "literatura de la revolución mexicana" (cfr. Olea, "La Novela", pássim). Tanto más oportuna resulta esta sugerencia, por cuanto permite relacionar la propia producción de EH con esta literatura (ver Bubnova, "La paloma, el sótano"). 
Si bien EH ha cobrado notoriedad y prestigio — principalmente póstumos - como narrador, ${ }^{3}$ acerca de su obra poética no he encontrado muchos comentarios concretos. Entre los pocos que hay, van en el sentido de que se trata de una poesía religiosa o, sumariamente, mística. Las alabanzas escurridizas de sus contemporáneos no agregan nada a su apreciación y eventual comprensión. Intento aquí una primera aproximación al conjunto de su poesía publicada, ${ }^{4}$ haciendo referencias cruzadas a ciertos fragmentos de su narrativa que pueden calificarse como líricos e introspectivos, y que hacen contrapunto con sus correspondientes pasajes poéticos. Se trata, sobre todo, de algunas páginas de la novela La paloma, el sótano y la torre (1949). La búsqueda de y la interpelación a Dios parece ser el tema que da unidad a su obra poética, y la pregunta acerca del bien y del mal, el centro de su preocupación ética. El viaje espiritual desde los “apagados muros" dentro de los cuales reina la soledad y la sordidez, y donde priva un tono de melancolía y de una silenciosa y resignada desesperación, pasa por el amor humano en el cual se encuentra un descanso provisional, tiene por objetivo la trascendencia (Primer ofrecimiento), pero por el camino se pierde el tino pues hay conciencia de que se ha partido del pecado original (El día que perdimos la inocencia), mientras que la redención cristiana parece ser insuficiente pues somos todos hijos de Caín.

La orientación formal evidente de prácticamente todos los poemas de EH es hacia la poesía del Siglo de Oro, ante todo se trata de los modelos de san Juan de la Cruz, fray Luis de León, santa Teresa de Jesús, en parte Góngora (Soledades), con su versificación, tópica y tónica, sea religiosa, sea profana. El uso sistemático pero bastante libre de silvas y, en parte, de las más rigurosas liras (Beatus ille) es totalmente explícito (registrado en sus ensayos como modelo a seguir) y esperadamente identificable. ${ }^{5}$ Pero desde luego no se trata de agotar el sentido de la

${ }^{3}$ Principalmente se analizan y se exaltan sus cuentos, por el carácter ambivalente, irónico y autorreferente de su escritura, y en menor escala, la novela.

${ }^{4}$ Por el Fondo de Cultura Económica Entre apagados muros (1943) y publicaciones en la revista América, recogidos como Otros poemas.

${ }^{5}$ La silva de por sí marca la tendencia hacia el verso libre, que desde luego abunda en EH, además en formas más diversas; también aparece algún poema en prosa, de modo que sería incorrecto limitar la descripción de la versificación hernandiana a liras y silvas. Por lo demás, este breve estudio no pretende un examen sistemático de la versificación de EH. 
referencia por las tradicionales "influencias", ya que el uso que les da EH a las clásicas formas y los muy antologados tópicos sólo se puede entender como una respuesta cuestionadora de su propia realidad puesta en la perspectiva de la tradición poética al límite de sus posibilidades. Las referencias al Antiguo (p. e. Job) y al Nuevo Testamento (la pasión de Cristo) están, al parecer, al servicio del mismo propósito de poner en crisis, mediante la contradicción, aparentemente renovadora y a la vez tópica, que consiste en echar en odres viejos vino nuevo, un nuevo contenido haciéndolo estallar dentro del antiguo molde mediante la inversión del sentido.

Así el Beatus ille (un guiño más hacia fray Luis que hacia Horacio), con el subtítulo de reconsideración, una especie de invocación del lugar común cuyo sentido radicaliza mediante inversión, convierte el "mundanal ruido" en "casi sólo un gran gemido" del mundo en sufrimiento. Las inusuales referencias en $\mathrm{EH}$ a los tópicos históricos y sociales del momento, pasados por la referencia literaria actualizada, como "Los de abajo, por nombre / llevan, el vulgo vil, la amorfa masa, / y, sin embargo, hombre / es ahí el hombre, y pasa, / uno a uno su bien, su mal, su vida escasa" ( $O C, \mathrm{I}, 84-85)$, mientras que "el dorado techo / nunca sin culpa alzado, / es, y más negro, mientras más dorado", cuestionan, con estoicismo, la misma posibilidad de una "regalada vida". El lamento acerca del "ya automatizado vivir" característico de la existencia contemporánea no permite tan siquiera una ilusión acerca de la posibilidad de una "mejor vía" (87), que no la halla la "airada inteligencia" aparentemente por la insolidaridad que priva dentro de una "ciudad henchida", referencia en la que ya adivinamos la expansión posterior de nuestra gran metrópolis. La visión del paisaje solitario observado desde un punto elevado no invita a una conversación con Dios cuando se sabe que en seguida hay que volver a la guerra y la rutina de la vida diaria la cual deja escaso margen a la creatividad del espíritu. El alma aprisionada por el cuerpo en su anhelo vagamente neoplatónico busca la luz pero, contradictoriamente, no se atreve a mirarla de frente. La sed de una iluminación podría interpretarse como una búsqueda infructuosa de la experiencia mística en una plegaria dirigida al sueño y a la muerte. La versificación basada en el recurso a la reiteración, repetición de vocablos y giros, cuya monotonía deliberada parece denotar la desesperada 
pérdida de finalidad ("no tiene objetivo el ansia mía", 75), la profunda decepción y la inminencia de la muerte como lo "inalumbrable": "Pues en verdad venimos / de lejos, / y en verdad vamos lejos" (78). El mismo amor se concibe a sí mismo como un permanente e ineludible fracaso, a pesar de la tregua provisional que el amor y el contacto con lo bello proporcionan.

En general, la poética del rechazo de EH propone conceptos mediante la creación de vocablos — nombres sustantivos y adjetivos - por medio de la negación de esencias. Si se afirma la inteligencia, su contraparte es una "ininteligencia".

En cuanto al tema religioso, el escepticismo y a lo más un ansia de la fe, y no el rapto místico, alienta "la conciencia errante del poeta" (32) en más de una ocasión. Lleva a una crisis mediante la confrontación entre forma y contenido en la Imagen de María, donde propone el siguiente oxímoron: "Tus dulces ojos falsos", que agrega una inquietante ambivalencia a la alusión a la Virgen. Sorprenden asimismo "La tierna torre y cándida / serpiente inmaculada de tu cuello" (33), convocando imágenes de doble filo, que reúnen los tópicos asociados a la Virgen ("los pies de la luna”, marca inequívoca de la inmaculada concepción, 35), con los del pecado original y aun con el paganismo: "tus pies, manzanas tibias, dulces rosas / de olor, por quien quitara / mi pan, yo, de mi boca, de su hocico, / la sierpe, la manzana, / y de sus belfos ácidos, / Pan, la fragante flauta". Un rapto místico es más bien lo que anhela el poeta: "[...] enloquéceme, / hazme creer el encanto, solamente / hazme creer el encanto de que existes, / ciega mi entendimiento, / la luz, la necesito, / más en el corazón" (35). Como se puede ver, aquí se trata de la duda y de una lucidez al menos agnóstica, más que de una fe incuestionable. Inusitada, una tópica semejante no es del todo injustificada, por la conocida interpretación teológica de María como una nueva Eva redentora (como su hijo Jesús es nuevo Adán), pero la ambivalencia salta a la vista.

Ahora bien, el poeta retoma las formas y tópicos de la poesía religiosa para una búsqueda intrínseca de sí mismo en forma de dos "ofrecimientos", 6 que se hacen al "amante", y no al Amado como se espe-

${ }^{6}$ Los "ofrecimientos" se hacen, dentro de la práctica católica, a Jesucristo, a la Virgen María y eventualmente a san José, partiendo del ofertorio que habría hecho de su 
raría (cfr. san Juan de la Cruz), es decir, a un Jesucristo, pero ahora "sin voz, sobrecogido, traspasado" y, además, "viudo" (26). Al parecer, estos "ofrecimientos" van dirigidos al "hombre interior" (para expresar este tópico de introspección cristiana con las palabras, por ejemplo, del capitán Francisco de Aldana, en el soneto "El ímpetu cruel de mi destino...", para justificar la tónica áurea). ${ }^{7}$ Entonces se trata de una especie de identificación del sujeto con Cristo, o, concedamos, la reversibilidad del amor divino hacia la creatura a partir del amor de ésta por su Creador. Se mira a sí mismo con: "autoscópicos seres [que] son mis ojos" (OC, I, 43); es decir, son capaces de ver tanto por fuera como por dentro del yo, donde encuentra una otredad. Y dice entonces a este su otro yo, patético en su indigencia, soledad y abandono: "tú eres igual a mí, ven, hablaremos" (26), y luego una vez más: “tú eres igual a mí, / tú sí me escucharás, ven, hablaremos" (29).

Modelos medievales y renacentistas evocan las reflexiones lírico-filosóficas puestas en el marco de los contrafacta de los géneros y formas litúrgicas, tales como los mencionados "ofrecimientos" (que originalmente son los "ofrecimientos de la preciosa sangre de Jesús a su Padre"), o como Acto de fe (76), más metafísico que cristiano.

En el segundo "ofrecimiento", existencialista, el "tú", o sea "el amante que ha caído en desgracia", aparece bajo metáfora de "aguja", que por asociación de ideas relaciono con otro poeta metafísico, bastante lejano de $\mathrm{EH}$, el ruso Joseph Brodsky, en el cual la metafísica "aguja" cose la esencia a la existencia, tratando de remendar el agujero que se manifiesta entre la vida perecedera y sujeta a la muerte y la trascendencia, en $L a$ gran elegía a John Donne (1963).

Lo erótico también se expresa dentro de la tópica cristiana (A Beatriz), y de acuerdo con la tradición mística, pero quién sabe si tan ortodoxa, porque aquí la carne se exalta y se eleva hacia la dimensión divina, y no al revés, cuando en medio de la elevación a Dios la co-

sangre redentora el propio Hijo del Hombre a su divino Padre. EH ofrece dos: el primero "Se hace al amante que ha conocido el fin de sus trabajos". El otro "Se hace al amante que ha caído en desgracia". El carácter laico de los dos me hace pensar en los que Bajtín llamó, inexactamente, "parodia sacra" y que no es sino "contrahechura" de las formas litúrgicas y de la práctica católica de la devoción.

${ }^{7}$ Aunque yo no haya encontrado en los textos de EH referencias a lecturas de Aldana. 
munión mística pasa por la tópica del amor humano y terrenal "nos funde el óleo / sacramental que obra en nuestros huesos. / Oh devoción recíproca, / función ultraterrena que sublima / los jugos de la carne, y torna templo / de comunión, la médula profunda" (31). Lo menos que se puede decir es que se aparta de la ortodoxia e incursiona en terrenos aledaños a la mística.

Las referencias a los conocidos pasajes de la poesía áurea ("Los árboles, el monte, los collados", 38) contrastan con la idea de la desintegración, tan opuesta a la plenitud del Ser de la mística española, porque "se ha perdido / dentro de sí tu ser, y manifiesto / documento de sed y de insolvencia" (39). ${ }^{8}$ En la "noche oscura" de la existencia, iluminada por "la solitaria y pura inteligencia" (62), el poeta interroga acerca del sentido de la vida, cavilando si no ha perdido el tino, y entrevé sólo una puerta, aquella abierta hacia la muerte.

Aquí, como en otros pasajes líricos, emerge la oposición constante del planteamiento ético básico de EH: entendimiento / corazón. El tema de la inteligencia frente a, digamos, "ininteligencia" o la torpeza del alma, atraviesa toda su obra ensayística e inaugura la narrativa de $L a$ paloma, el sótano y la torre, desdoblando, como los críticos dicen, al propio prototipo del héroe en dos personajes: ${ }^{9}$ Catito y Fulán. La "alada, fúlgida, lustral y omnipresente inteligencia" aquí aparece como una insuficiencia si está ausente en ella el sentido ético de la bondad (60) y preocupación por el otro. Al final de la novela, el primero arroja, simbólica y alegóricamente, al segundo en un precipicio, como cumpliendo obligadamente con el reto de una traición primigenia (Caín y Abel), llevada a cabo en el escenario de la vida introspectiva. Así, triunfa trágicamente la parte "mala" del ser humano, dejándonos muy pocas expectativas en cuanto al futuro de la humanidad. ${ }^{10}$

El planteamiento básico de la obra de EH es ético más que formal, aunque lo disfrazara cuidadosamente de uno puramente estético, impo-

${ }^{8}$ Asimismo cfr.: "sediento / e insolvente soy" (42), y aun de "ojos sitibundos" (113).

9 Ahora bien, tal ocurrencia sólo es válida si realizamos la no del todo correcta, desde el punto de vista teórico, identificación entre autor y sus personajes mediante el recurso anticuado al "prototipo".

${ }^{10}$ En una lectura alegórica, se puede leer el episodio final como un suicidio (moral y físico) de la humanidad, lo cual le contribuye una inquietante actualidad. 
niendo definiciones paradójicas y tautológicas sazonadas con la sal de su ironía en Bosquejos. La torre y el sótano, alusión encubierta, enigmática, a las dos dimensiones del alma humana, son el símbolo de las contradicciones desgarradoras del ser humano planteadas en forma de una metafísica del bien y del mal (lo contrapuntean las parejas de oposiciones que aparecen como títulos de los capítulos de la novela). Ahora bien, las metáforas de la torre y del sótano aparecen no sólo en la poesía (cuencas, abismos, honduras, fondos, etc.), y en la novela, sino también en el ensayo, como los ambivalentes "arriba y abajo". Pero la oposición no se limita, al parecer, a la demasiado transparente oposición, sino que: "el uno está arriba, pero no como torre fincada, como viento; y el otro está abajo; pero no como sótano, como madre de aguas, como vena latente, como raíz de ríos perpetuos, de corrientes que crecen con los siglos" (Bosquejos, 34). No obstante, también a éstas se le opone "un manantial de sed [...] de aguas sin raíz" (93). Entonces, los "arriba" y "abajo" implican no sólo una topología moral, sino también una social y/o existencial, pensada polisémicamente.

A pesar de su aparente repugnancia por la teoría y la inclinación hacia una "filosofía" espontánea, irónica y cáustica, que todavía espera su intérprete, EH sitúa una reflexión especulativa acerca de la esencia de lo poético en un ensayo periodístico y en un poema. De ahí tenemos un Sumarísimo extracto de una definición (oc, I, 79) y "Una definición de poesía" (Bosquejos, 165).

La lírica suele ser seria y, en tiempos, hasta solemne cuando no es irónica, pero no hay ni una pisca de ingenuidad en el uso de todos estos elementos "anticuados": bajo una luz humorística, apropiada en una novela, se pone de manifiesto la conciencia de la forma y la distancia emotiva y respecto de su uso, gesto mediador que se suspende en un texto paladinamente lírico; en cambio en la prosa (La paloma...) irrumpe un comentario autoirónico: “¡Ay, qué cosas! Así se escribía en aquellos tiempos" (406).

Ahora bien, la experiencia espiritual distanciada tal vez de la mística religiosa sí aparece representada en La paloma, el sótano y la torre en forma de lo que Michel Hulin llama la "mística salvaje", experiencia espontánea del contacto con la trascendencia. Fulán en su trayectoria interior pasa por una especie de "rapto místico", durante el cual vislumbra 
"otra realidad", siendo que "[e]l paisaje, aunque para él era desconocido, le interesaba poco, ya que más bien se entretenía en mirar ojos adentro. Su espíritu se abría a una expectación no usual en él, a una actividad introvertiente, a un revertimiento autónomo, espontáneo" (OC, I, 366). Fulán se ve a sí mismo en un espejo como a otro, y no se reconoce. En la "otra realidad" transformada se encuentra, previa y platónicamente, con Juana Andrea, su amor, de modo que cuando se topa con ella en ésta, no se acuerda del encuentro anticipado, aunque la reconoce con el "corazón".

"El poema se hurta a las mareas, y se salva y redime del declinar del tiempo", según la expectativa de EH (Franco, en Bosquejos, 35). Aunque por lo pronto lo que más se muestra rescatado de los olvidos y omisiones es la prosa de $\mathrm{EH}$, mientras que su obra poética permanece desatendida, los versos son el imprescindible complemento para acercarnos al proyecto global del autor. La novela le hace una contraparte y vislumbra una completud más allá de la ficción, permitiendo adivinar el sentido de la totalidad del viaje espiritual de EH. Si la poesía muestra la fatal insatisfacción de la búsqueda de la unión con la trascendencia, marcando la inevitable separación entre la carne y el espíritu, la novela trata de mostrar el porqué, al plantear la elección moral mediante cierta obtusidad del alma ("el corazón yace pesado, gordo, cegado, obtuso", $O C, \mathrm{I}, 295)$. Y el problema se plantea canalizado mediante la "carne", es decir, el sexo. La novela tiene los ingredientes indispensables de atracción que consisten en cierto costumbrismo histórico, la ironía y aun la comicidad y, como marca de la modernidad, la conciencia de sí mismo por parte del narrador, desdoblado, en cuanto héroe (como he mencionado), en dos personajes narrados en ópticas distintas: una confesional y otra objetivadora. Curiosamente, la última corresponde a la descripción del introspectivo, reservado pero noble Fulán, mientras que la confesión retrospectiva la realiza quien fuera, a los catorce años, el malicioso Catito, incapaz de dominar la repentina sensualidad propia de la adolescencia. Pero su vitalidad y sentido crítico anticipan la capacidad de realizar un examen futuro de su interioridad. Y todo esto sí hace pensar en una práctica religiosa y hasta monástica, dentro de una disciplina religiosa, aunque sin relación alguna con la institución de la Iglesia.

Pero el elemento más sustancial, la crítica autoconsciente de la moral personal, que sobre el fondo de la crítica social predominante en la no- 
vela de la revolución se veía ajena al aire del tiempo que demandaba el análisis de las manifestaciones colectivas, y que incluso hasta ahora no resulta atractivo no sólo para el lector sino casi por cualquier representante de la cultura contemporánea; lector que se siente agredido por las demandas éticas del desdoblado narrador, al parecerle extemporáneas, excesivamente moralizantes y canceladas por la psicología moderna. El lector defiende su libertad de elección privilegiando el cuerpo y el sexo como remedio personal — sin pensar en su potencial de agresión-, aunque deriven en un engaño y, en perspectiva, en la muerte, sin admitir la inferencia de ninguna moralina. EH en cuanto lector de sí mismo no es así.

Me parece que hay una determinada afinidad entre la postura ética y moral de eH y la de su contemporáneo, el filósofo colombiano Fernando González (1894-1964) ${ }^{11}$, que plantea la libertad del ser humano en términos parecidos. "El hombre no es libre, pero la inteligencia lo liberta” (11) propone FG. ¿En qué forma? "La inteligencia objetiva nuestros actos y los critica: nos objetivamos y nos criticamos". Si bien el colombiano recurre a la ética cristiana directamente, es asimismo un devoto del conocimiento, de la ciencia e incluso de la psicología contemporánea, y no un retrógrada que invite a mirar hacia atrás, hacia modelos obsoletos. Ahora bien, lo mismo que EH, con su permanente tendencia a una disertación en torno al bien y el mal, FG tampoco va a gustar, porque de hecho propone: "La inteligencia liberta al hombre por medio del siguiente mecanismo: conocimiento (ideal); remordimiento (desprecio del instante presente); arrepentimiento, tentación, etc. Fenómenos morales" (11). Así, "[e]l camino a la verdad es la renuncia” (32). La obra El remordimiento, a caballo entre memoria y tratado moral, cuenta en qué forma había logrado FG, renunciar a varias "tentaciones" carnales, entre ellas destaca sobre todo una: la joven Toní. FG es un hombre de

${ }^{11}$ Este interesante pensador, que trató temas semejantes y paralelos a Vasconcelos, Samuel Ramos y Octavio Paz, prácticamente se desconoce en México. La identidad latinoamericana y el futuro de la "raza", que vislumbra en la figura del "futuro mulato", es un tema consonante con la "raza cósmica" de Vasconcelos. El existencialismo sui géneris y el latinoamericanismo, frente a la identidad colombiana, hacen recordar a Ramos y a Paz (quien sí conoció a FG) en su propio ámbito nacional. La identidad como tópico recurrente permite un rescate de estas ideas, junto con la ética personalista, para el contexto contemporáneo. 
cuarenta años, diplomático, casado, con cinco hijos, pero oportunidades no le faltan. Luego él se arrepiente toda su vida de haberlas dejado, pero con todo, muestra el proceso intelectual y moral mediante el cual lo había logrado como un triunfo. En el fondo están las posiciones paulinas de diferenciar entre alma-cuerpo-espíritu (p. e. Cor. I, 15), y el espíritu inmortal ${ }^{12}$ es, sin duda, el beneficiario de la tal hazaña, porque el cuerpo (los instintos) es lo que nos homologa con los animales irracionales.

Bueno, esta digresión se refiere a una afinidad de preocupaciones ético-estéticas; EH las plantea bajo el sesgo de tres posibilidades de género cultivadas por él, que permite la escritura literaria: poesía/narrativa/ ensayo. La experiencia propiamente espiritual se acerca a la posibilidad de la comunión con Dios o con la trascendencia como un desideratum, en forma objetivada, como una representación o como una vivencia poética, el pesimismo y la duda incluidos. El renunciamiento atraviesa su vida y su obra sin manifestación visible, porque ante todo pertenece a la categoría de lo no decible y no dicho dentro de los valores y creencias de una cierta época, y sin embargo se encuentra ahí listo para emerger como la lectura posible de un texto "[...] en insolutas / e inéditas volutas de plegaria, / debajo está el escorzo del anhelo" (OC, I, 55). Un eco remoto de aquel lenguaje auténtico, "original”, al que alude Walter Benjamin tal vez resuena en esta preocupación ética dirigida hacia el mismo sujeto, situación que hace comprensible el trasfondo de esta poesía. Nunca se le podrá reconstruir sino fragmentariamente, sin embargo se sabe que en alguna parte está y su posibilidad sólo es sugerida por la escritura poética.

\section{REFERENCIAS}

Benjamin, Walter, "La tarea del traductor" [1923], en Angelus Novus, Barcelona, Edhasa, 1971, 127-143.

Bubnova, Tatiana, "La paloma, el sótano y la torre de Efrén Hernández y novela de la revolución mexicana", en Coloquio de literaturas mexicanas, 16, 1997, 15-36.

12 "Si los muertos no resucitan, comamos y bebamos, que mañana moriremos" (Cor. I, XV, 13-14). 
Directorio Eucarístico, Ejercicios, meditaciones y oraciones para la confesión y comunión ..., $4^{\mathrm{a}}$ ed., México, Imprenta de J. M. Lara, 1866.

GonZÁlez, Fernando, El remordimiento (Problemas de teología moral) en $<$ www.otraparte.org/ideas/pdf/1935-remordimiento.pdf $>$.

HeRnández, Efrén, Bosquejos, edición, prólogo, notas e índices de Lourdes Franco Bagnouls, México, Universidad Nacional Autónoma de México, 1995.

Hernández, Efrén, Obras completas, I, ed. y prólogo de Alejandro Toledo, México, Fondo de Cultura Económica, 2007.

Hulin, Michel, La mistica salvaje. En los antípodas del espiritu, trad. María Tabuyo y Agustín López, Madrid, Siruela, 2007.

Olea Franco, Rafael, "La Novela de la Revolución Mexicana: una propuesta de lectura", Nueva Revista de Filología Hispánica, 60 (2), 2012, 479-514.

Rodríguez, Itzel, "La vanguardia solitaria: Efrén Hernández", Decires (Universidad Nacional Autónoma de México), Nueva Época, vol. 11, núm. 1213, 2008, 101-113.

Zaehner, Robert Charles, Mysticism. An Inquiry into some Varieties of Praeternatural Experience, Oxford, Clarendon Press, 1957. 